\title{
An Update on Medication Use in Older Adults: a Narrative Review
}

\author{
Heather E. Barry ${ }^{1}$ (D) - Carmel M. Hughes ${ }^{1}$ (D) \\ Accepted: 4 May 2021 / Published online: 20 July 2021 \\ (C) The Author(s) 2021
}

\begin{abstract}
Purpose of Review The global phenomenon of population aging is impacting the health and care needs of society. The use of medications by older adults is acknowledged to be the most common form of medical intervention for many acute and chronic conditions and prescribing in this population continues to increase. In this narrative review, we summarise the age-related factors that should be considered when prescribing for older adults, address some of the perennial challenges related to medicine use in older people, and highlight important emerging research in this area.

Recent Findings A range of age-related factors should be considered when prescribing for older adults. However, the evidence base still lacks data pertaining to older adults due to their continued under-representation in clinical trials. Multimorbidity, polypharmacy, and inappropriate prescribing continue to remain prevalent among older adults, although recent research has been focused on the development and evaluation of complex interventions to address these challenges.

Summary Further high-quality studies of interventions to improve and support medication use in older adults are needed, ensuring that older adults are well represented in such trials and consideration is given to the measurement of patient- and provider-focused outcomes.
\end{abstract}

Keywords Aging $\cdot$ Medications $\cdot$ Medication adherence $\cdot$ Older adults $\cdot$ Outcome measures $\cdot$ Polypharmacy $\cdot$ Prescribing

\section{Introduction}

Population aging is occurring globally; the number of people aged 60 years and over has more than doubled since 1980 and it is estimated that this figure will double again by 2050 [1]. Whilst this demographic shift is representative of advances in medicine, technology, and public health, it also poses significant and widespread challenges to society [2]. One aspect of this is the changing burden of disease, with an overall shift from communicable diseases to chronic, non-communicable diseases $[3,4]$. Whilst chronic conditions such as heart disease, stroke, chronic obstructive pulmonary disease, and cancer are acknowledged to be leading contributors to global deaths and disability [5], other conditions which are increasing in prevalence such as dementia, diabetes, and Parkinson's

This article is part of the Topical Collection on Epidemiology of Aging

Carmel M. Hughes

c.hughes@qub.ac.uk

1 Primary Care Research Group, School of Pharmacy, Queen's University Belfast, Medical Biology Centre, 97 Lisburn Road, Belfast BT9 7BL, UK disease are projected to have a greater effect on death and disability over the coming years [6-9].

Multimorbidity, defined as the presence of two or more chronic conditions - both diseases and geriatric syndromes such as frailty [10] - is a mounting global public health challenge as our population ages $[11,12]$ and is associated with poorer health outcomes, reduced quality of life, and increased healthcare costs [13]. With the resultant increasing complexity of managing multimorbid older adults, comes the consequence of greater treatment (specifically medication) burden. Medication usage and polypharmacy (the concurrent use of multiple medications) have increased markedly over the last number of decades $[14,15 \cdot \bullet]$. The use of potentially inappropriate medications (PIMs), where potential harms outweigh potential benefits, is also prevalent among older people and associated with higher rates of healthcare utilisation and costs $[16 \bullet, 17]$. As a result, these complicated and intertwined issues of multimorbidity, polypharmacy, and prescribing appropriateness in older adults have been the focus of much research activity in recent years and the evidence-base is rapidly expanding.

Therefore, in this paper, we aim to summarise the agerelated factors that should be considered when prescribing for older adults, address some of the key and persistent 
challenges relating to medicine use in older people such as polypharmacy and appropriateness of prescribing, highlight important emerging research in this area relating to intervention development and evaluation as well as the increasing importance of defining core outcome sets (COSs) for trials within this research field, and provide recommendations for future research.

\section{Search Methods}

A literature search was conducted for relevant literature published since 2016 (i.e. last 5 years) using PubMed, Web of Science, and the Cochrane Library of Systematic Reviews. The following search terms were used: 'older adults', 'older people', 'elderly', 'aged', 'medicines', 'medications', 'prescribing', 'polypharmacy', 'multimorbidity', 'primary care', and combinations thereof. The authors' existing knowledge of literature was also used to identify relevant references, and we hand-searched reference lists of identified articles to identify additional papers. Only peer-reviewed articles published in English were selected. Our focus for this review was papers focusing on the primary care setting with community-dwelling older adults or those residents in care homes; we therefore excluded studies of older adults in secondary care or hospice settings as this was considered outside the scope of the current review.

\section{Age-Related Prescribing Considerations}

As a person ages, there are many normal physiological changes that take place which may affect the way in which a person processes and responds to medications. For example, reductions in gastric motility, lean body mass and body water, blood flow, and renal and hepatic function can all affect drug pharmacokinetics (absorption, distribution, metabolism, and excretion) [18-20]. Age-related pharmacodynamic changes may also occur which can increase an older person's sensitivity to several drug classes, such as anticholinergics, benzodiazepines, and opioids [19, 21]. Adverse effects associated with such drugs may therefore be potentiated. Changes in pharmacokinetics and pharmacodynamics may be amplified in older adults with frailty, making them particularly vulnerable to adverse drug events $[22,23]$. Whilst beyond the scope of this paper, a recent review has considered medication use in frailty in more detail [24].

Additional age-related changes should also be considered during the prescribing process to ensure optimal medication safety and reduce medication-related harm. Sensory impairment, particularly vision and hearing loss, and issues with swallowing, manual dexterity, and co-ordination may affect a person's ability to acquire, administer, manage, and adhere to their medication regimen [19, 25-27]. Declining cognitive function and/or the presence of intellectual disability in older adults may also present challenges during prescribing if patients are unable to participate in shared decision-making and communicate their beliefs and preferences, as well as affecting medication management abilities [19, 28, 29]. Prescribers should be cognisant of older adults' use of non-prescription medications, particularly given the fact that they have been shown to be high users of over-the-counter (OTC) and complementary and alternative (CAM) medicines [30-33], placing them at greater risk of potential medication-related harm through drug interactions $[34,35]$. It is apparent that prescribing for older adults is not free from ambiguity or uncertainty when taking these factors into account during the prescribing process. Prescribers may be guided by accessing an appropriate evidence base; however, this is somewhat limited by the fact that such treatment guidelines often contain insufficient clinical trial data relating to older adults.

\section{Inclusion of Older Adults in Clinical Studies}

It is acknowledged that older adults are excluded or underrepresented in clinical trials [36•, 37-40]. Although age representation in influential cardiology clinical trials has been reported to have increased modestly over the last two decades, gaps in the representation of older adults still exist [41, 42]. A recent study which examined the representation of older adults in phase III clinical trials funded by the National Institutes of Health $(\mathrm{NIH})$ found that one-third of studies had arbitrary upper age thresholds [36•]. However, beyond age, older adults are found to have often been implicitly excluded based on polypharmacy or comorbid conditions [36•, 43, 44•]. A review conducted by $\mathrm{He}$ and colleagues which examined the percentage of clinical populations with a physical health condition who would be excluded by randomised controlled trials for that condition concluded that trial evidence is typically derived from narrow populations selected to have a lower risk of adverse effects, by selective exclusion of patients with comorbidity, co-prescribing, and frailty [44•]. Clearly, this represents a major paradox as the older population uses the most medication due to multimorbidity and are most frequently exposed to adverse drug reactions; therefore, data from such trials are not as relevant to more complex patients. Furthermore, the outcomes from trials which are underrepresentative of older people may not be generalisable to the older population [45]; the importance of outcomes is discussed later in this review. Over the past year, it has become evident that older adults are even under-represented in COVID-19 trials, despite being one of the populations most affected by and at risk from COVID-19 infection [46-48]. Studies have taken a siloed approach as to how comorbidities and age affect outcomes from COVID-19 
infection [46, 49], and there have been calls for COVID-19 research to be more inclusive of older people with frailty, cognitive impairment, and multimorbidity $[46,50]$.

There have been promising changes in trial inclusion, some of which have been mandated by government and/or regulatory bodies. For example, the NIH implemented a new policy in 2019, which mandates that all NIH-funded clinical studies must include people across the lifespan [51], and the Food and Drug Administration has issued draft guidance for inclusion of older adults in cancer clinical trials [52]. Whilst challenges remain to ensure that changes in such inclusivity practices take effect, particularly in cardiovascular research [53, 54], some improvements in the recruitment of older adults have been observed in cancer clinical trials [55] which will allow evidence to emerge in these fields.

\section{Prescribing in the Face of Multimorbidity}

The evidence base has informed guidelines which traditionally have been focused on single conditions which, of course, can lead to polypharmacy. Despite many studies focusing on various aspects concerned with polypharmacy, one recurring problem is the difficulty and variation in the way in which it has been defined to date [56-58]. A review by Sirois and colleagues reported that more than 46 definitions of polypharmacy were retrieved from the literature [58]. Clearly, this makes exploring the prevalence of polypharmacy difficult and is one reason why such a range in prevalence has been reported [59•, 60••, 61-63].

Over recent years, the concept of appropriate versus inappropriate polypharmacy has been suggested as a more meaningful classification rather than using numerical thresholds $[56,64]$. Appropriate polypharmacy involves the prescribing of appropriate combinations of medications to people with multimorbidity, whilst inappropriate polypharmacy can give rise to potentially inappropriate prescribing and prescribing of potentially inappropriate medications [56, 57, 64]. Psychotropic polypharmacy remains problematic [65], and polypharmacy can be associated with certain classes of medications, particularly central nervous system (CNS) drugs, anticholinergics, sedatives, and proton pump inhibitors [66-68]. Several epidemiological studies have demonstrated that potentially inappropriate prescribing increases with polypharmacy [69-73]. Similar trends have been observed in care home populations and people with dementia [74, 75]. Prescribing cascades, where an adverse drug event is not recognised as such and an additional drug is prescribed to treat the drug-induced adverse event, may contribute to polypharmacy and create additional risks for multimorbid patients [76, 77]. McCarthy and colleagues have highlighted that appropriate and therapeutically beneficial prescribing cascades can also exist; analogous to the way that polypharmacy can be classified as appropriate or inappropriate, prescribing cascades may be appropriate or problematic [77]. 'Legacy prescribing' (drugs that should be prescribed for an intermediate period of time, longer than three months but not indefinitely, that are not appropriately discontinued) has also been identified as a contributor to polypharmacy, with antidepressants, bisphosphonates, and proton pump inhibitors commonly implicated [78]. Von Buedingen and colleagues have cautioned against cross-sectional assessments of medication use due to the frequent changes they observed in the medication regimens of older adults with multimorbidity and polypharmacy [79]. These are important considerations when interpreting epidemiological studies of polypharmacy and prescribing appropriateness, and the goal of achieving patientcentred care should not be forgotten. An international group of academics and clinicians have set out ten recommendations for action for reducing inappropriate medication use and polypharmacy; giving priority to patient and family preferences is emphasised [80].

Unsurprisingly, as the number of drugs prescribed to older adults increases, so too do issues with adherence. Increasing age is not necessarily a predictor of non-adherence, although adherence is more likely to be lowest in older age categories of older adults [81, 82]. There is greater recognition that adherence is a complex health behaviour with multifaceted determinants [83], and as a result, careful thought is needed when planning how to resolve barriers to adherence. For example, a recent study reported that cost-related medication nonadherence is becoming increasingly common among older adults in the USA [84]; however, there are myriad other reasons for medication non-adherence including patient-related, socioeconomic, and therapy-related factors [85]. This has important consequences for intervention developers who must take a broad and holistic approach to solving all medicationrelated challenges, not just those related to adherence.

\section{Interventions to Support Medication Use in Older Adults}

There is an increasing focus on developing, evaluating, and implementing interventions to support prescribing and medication use in older people. Over the last number of years, Cochrane reviews have been published on interventions to optimise prescribing for older people in care homes [86], improve the appropriate use of polypharmacy in older people [87], and improve medication-taking ability and adherence in older adults prescribed multiple medications [88]. Although each of these reviews was focused on different aspects of medication use in older adults, it is interesting to note that all concluded that there was great variability between the interventions that were included, making it difficult to draw 
firm conclusions. The need for high-quality studies, measuring well-defined and relevant outcomes has been emphasised.

It is evident from the literature that the development of complex interventions is increasingly following the United Kingdom's Medical Research Council guidance by taking a systematic approach underpinned by the evidence base and relevant theory and supported by thorough piloting and feasibility work [89]. Indeed, Patton and colleagues highlighted the need for a more robust theoretical basis for interventions targeting medication adherence in older adults [90]. A number of interventions to support medication use in older adults have been developed in this systematic manner [91-93]. The supporting prescribing in older patients with significant multimorbidity and polypharmacy (SPPiRE) intervention is designed to support general practitioners to reduce potentially inappropriate prescribing and consider deprescribing through an individualised structured medication review in older people with multimorbidity and polypharmacy in primary care in the Republic of Ireland [91]; the definitive RCT is ongoing. The Solutions for Medication Adherence Problems (S-MAP) intervention is theory-based and guides community pharmacists using a web application to identify medication adherence barriers and deliver individually tailored solutions (behaviour change techniques) [92]. It has undergone pilot testing in community pharmacies in Northern Ireland and England; whilst study procedures and intervention delivery were reported to be feasible, the authors plan to make modifications before progressing to a cluster RCT to explore intervention effectiveness [92]. Other approaches that have been utilised in interventions to support prescribing and medication use in older people include electronic clinical decision support systems [94, 95] and deprescribing [96, 97]. Whilst deprescribing interventions may reduce mortality and the use of potentially inappropriate medications, and improve medication adherence [96, 98, 99], the effect may not be sustained, and further research is needed to determine the optimal interval of repeated deprescribing interventions [97]. A multi-faceted intervention for primary care has been proposed that includes an adapted version of a deprescribing protocol which may reverse prescribing cascades [100]. Novel approaches continue to be discussed within the literature. For example, a recent study has identified a core set of 12 indicators of clinical importance considered relevant to polypharmacy appropriateness which could be used to target and monitor future polypharmacy interventions [101]. It has been suggested that pharmacogenomics might help in individualised deprescribing in older adults [102], whilst machine learning and big data analysis techniques have been used to predict, identify, and manage polypharmacy [103, 104]. It will be interesting to see how these areas may help to progress the field over the coming decades.
There is consensus in the literature that many published trials of interventions to support prescribing and medication use in older adults are heterogeneous with respect to the outcomes measured across studies or selectively report outcomes, making it difficult to conclude which interventions are most effective $[105,106]$. As a result, over recent years much work has focused on the development of Core Outcome Sets (COSs) to be used in trials focusing on optimising prescribing in care homes [107], medication review [108], multimorbidity [109], improving appropriate polypharmacy [110], and medicines management in people with dementia [111]. Aubert and colleagues have argued that studies of interventions to reduce inappropriate medications should include outcome measures that are more clinically meaningful and centred on both patients and healthcare providers [112]. Patient-centred outcomes research should be used to generate evidence to facilitate person-centred care, the importance of which has been increasingly recognised and forms a central tenet to many evidence-based clinical guidelines. It is important, therefore, that patients, carers, and healthcare professionals are included during the COS development process so that the final COS has relevance to all key stakeholders. Further work is needed to reach consensus-derived agreement on the selection of outcome measurement instruments in previously developed COSs.

\section{Conclusion}

This review examined some of the key pertinent issues facing older adults in relation to prescribing and the use of medicines. Multimorbidity, polypharmacy, and potentially inappropriate prescribing remain major challenges for healthcare providers, and future research must continue to focus on developing and evaluating novel interventions to address these challenges, with the recruitment of older people into the studies to assess effectiveness. Higher-quality studies of such interventions are needed, with a focus on measuring outcomes of clinical importance to key stakeholders.

Author Contribution Both $\mathrm{HB}$ and $\mathrm{CH}$ contributed to the writing and editing of the manuscript.

Funding Dr. Barry and Prof. Hughes currently hold a grant from the Special EU Programmes Body (SEUPB) and INTERREG VA (Crossborder Healthcare Intervention Trials in Ireland Network; CHITIN), outside the submitted work. Prof. Hughes is a co-applicant on a grant from the National Institute of Health Research Policy Research Programme on deprescribing in care homes for older people.

Availability of Data and Material Not applicable.

Code Availability Not applicable. 


\section{Declarations}

Ethics Approval Not applicable.

Consent to Participate Not applicable.

Consent for Publication Not applicable.

Conflict of Interest The authors declare no competing interests.

Open Access This article is licensed under a Creative Commons Attribution 4.0 International License, which permits use, sharing, adaptation, distribution and reproduction in any medium or format, as long as you give appropriate credit to the original author(s) and the source, provide a link to the Creative Commons licence, and indicate if changes were made. The images or other third party material in this article are included in the article's Creative Commons licence, unless indicated otherwise in a credit line to the material. If material is not included in the article's Creative Commons licence and your intended use is not permitted by statutory regulation or exceeds the permitted use, you will need to obtain permission directly from the copyright holder. To view a copy of this licence, visit http://creativecommons.org/licenses/by/4.0/.

\section{References}

Papers of particular interest, published recently, have been highlighted as:

- Of importance

•- Of major importance

1. United Nations, Department of Economic and Social Affairs, Population Divisions. World population ageing 2017 - highlights. 2017. Available at: https://www.un.org/en/development/desa/ population/publications/pdf/ageing/WPA2017_Highlights.pdf. Accessed 15 Mar 2021

2. Sander M, Oxlund B, Jespersen A, Krasnik A, Mortensen EL, Westendorp RGJ, et al. The challenges of human population ageing. Age Ageing. 2015;44(2):185-7.

3. GBD. 2019 Disease and Injuries Collaborators. Global burden of 369 disease and injuries in 204 countries and territories, 19902019: a systematic analysis for the Global Burden of Disease Study 2019. Lancet. 2020;396(10258):1204-22.

4. Dall TM, Gallo PD, Chakrabarti R, West T, Semilla AP, Storm MV. An aging population and growing disease burden will require a large and specialised health care workforce by 2025 . Health Aff. 2013;32(11):2013-20.

5. World Health Organisation. Global Health Estimates. 2020. Available at: https://www.who.int/data/global-health-estimates. Accessed 26 Mar 2021

6. Rowley WR, Bezold C, Arikan Y, Byrne E, Krohe S. Diabetes 2030: insights from yesterday, today and future trends. Popul Health Manag. 2017;20(1):6-12.

7. GBD 2016 Neurology Collaborators. Global, regional, and national burden of neurological disorders, 1990-2016: a systematic analysis for the Global Burden of Disease study 2016. Lancet Neurol. 2019;18(5):459-80.

8. Wittenberg R, Hu B, Barraza-Araiza L, Rehill A. Projections of older people living with dementia and costs of dementia care in the United Kingdom, 2019-2040. 2020. Available at: https://www.lse. ac.uk/cpec/assets/documents/cpec-working-paper-5.pdf. Accessed 26 Mar 2021

9. Alzheimer's Association. 2020 Alzheimer's disease facts and figures. Alzheimers Dement. 2020;16(3):391-460.

10. Lee PG, Cigolle C, Blaum C. The co-occurrence of chronic disease and geriatric syndromes: the health and retirement study. J Am Geriatr Soc. 2009;57(3):511-6.

11. Nguyen H, Manolova G, Daskalopoulou C, Vitoratou S, Prince M, Prina AM. Prevalence of multimorbidity in community settings: a systematic review and meta-analysis of observational studies. J Cormorb. 2019;9:2235042X1987093. https://doi.org/10. 1177/2235042X19870934.

12. Ofori-Asenso R, Lee Chin K, Curtis AJ, Zomer E, Zoungas S, Liew D. Recent patterns of multimorbidity among older adults in high-income countries. Popul Health Manag. 2019;22(2):12737.

13. Marengoni A, Angleman S, Melis R, Mangialasche F, Karp A, Garmen A, et al. Aging with multimorbidity: a systematic review of the literature. Ageing Res Rev. 2011;10(4):430-9.

14. Charlesworth CJ, Smit E, Lee DSH, Alramadhan F, Odden MC. Polypharmacy among adults aged 65 years and older in the United States: 1998-2010. J Gerontology A Biol Med Sci. 2015;70(8): 989-95.

15.• Gao L, Maidment I, Matthews FE, Robinson L, Brayne C. Medical Research Council Cognitive Function and Ageing Study. Medication usage change in older people $(65+)$ in England over 20 years: findings from CFAS I and CFAS II. Age Ageing. 2018:47(2):220-5 Data were analysed from two separate population-based studies of older people aged $\geq 65$ years in England conducted two decades apart, the Cognitive Function Ageing Study I (1991-1994) and II (2008-2011). Findings from these studies showed a dramatic increase in the total amount of medication over two decades. The number of people taking $\geq 5$ medications increased from $12.2 \%$ in CFAS I to $49.6 \%$ in CFAS II. Age, number of longterm conditions, and living in a care setting were strongly associated with increased use of medication.

16.• Clark CM, Shaver AL, Aurelio LA, Feuerstein S, Wahler RG, Daly CJ, et al. Potentially inappropriate medications are associated with increased healthcare utilisation and costs. J Am Geriatr Soc. 2020;68(11):2542-50 Retrospective cohort study using Medical Expenditure Panel Survey data from 2011 to 2015. The prevalence of potentially inappropriate medication (PIM) prescribing over the 5-year study period was reported to be 34.4\%, showing that PIMs continue to be prescribed at high rates in the USA. The findings suggested that receipt of PIMs was associated with higher rates of healthcare utilisation (e.g. hospitalizations, Emergency Department visits) and increased costs across the healthcare continuum.

17. Fralick M, Bartsch E, Ritchie CS, Sacks CA. Estimating the use of potentially inappropriate medications among older adults in the United States. J Am Geriatr Soc. 2020;68(12):2927-30.

18. Giarratano A, Green SEL, Nicolau DP. Review of antimicrobial use and considerations in the elderly population. Clin Interv Aging. 2018;13:657-67.

19. Drenth van-Maanen AC, Wilting I, PAF J. Prescribing medicines to older people - how to consider the impact of ageing on human organ and body functions. Br J Clin Pharmacol. 2020;86(10): 1921-30.

20. Stader F, Kinvig H, Penny MA, Battegay M, Siccardi M, Marzolini C. Physiologically based pharmacokinetic modelling to identify pharmacokinetic parameters driving drug exposure changes in the elderly. Clin Pharmacokinet. 2020;59(3):383-401.

21. Thürmann PA. Pharmacodynamics and pharmacokinetics in older adults. Curr Opin Anaesthesiol. 2020;33(1):109-13. 
22. Hilmer SN, Wu H, Zhang M. Biology of frailty: implications for clinical pharmacology and drug therapy in frail older people. Mech Aging Dev. 2019;181:22-8.

23. Liau SJ, Lalic S, Sluggett JK, Cesari M, Onder G, Vetrano DL, et al. Optimizing Geriatric Pharmacotherapy through Pharmacoepidemiology Network (OPPEN) Medication management in frail older people: consensus principles for clinical practice, research and education. J Am Med Dir Assoc. 2020;22(1): 43-9.

24. Hogan DB, Maxwell CJ. Frailty and unintended risks of medications. Curr Epidemiol Rep. 2020;7(1):16-24.

25. Alhusein N, Macaden L, Smith A, Stoddart KM, Taylor AJ, Killick K, et al. 'Has she seen me?': a multiple methods study of the pharmaceutical care needs of older people with sensory impairment in Scotland. BMJ Open. 2018;8:e23198.

26. Lau ETL, Steadman KJ, Cichero JAY, Nissen LM. Dosage form modification and oral drug delivery in older people. Adv Drug Deliv Rev. 2018;135:75-84.

27. Schenk A, Eckardt-Felmberg R, Steinhagan-Thiessen E, Stegemann S. Patient behaviour in medication management: findings from a patient usability study that may impact clinical outcomes. Br J Clin Pharmacol. 2020;86(10):1958-68.

28. Dooley J, Bass N, Livingston G, McCabe R. Involving patients with dementia in decisions to initiate treatment: effect on patient acceptance, satisfaction and medication prescription. Br J Psychiatry. 2019;214(4):213-7.

29. Smith MVA, Adams D, Carr C, Mengoni ME. Do people with intellectual disabilities understand their prescription medication? A scoping review. J Appl Res Intellect Disabil. 2019;32(6):137588.

30. Qato DM, Wilder J, Schumm P, Gillet V, Alexander GC. Changes in prescription and over-the-counter medication and dietary supplement use among older adults in the United States, 2005 vs 2011. J Am Med Assoc. 2016;176(4):473-82.

31. Agbabiaka TB, Wilder B, Watson LK, Goodman C. Concurrent use of prescription drugs and herbal medicinal products in older adults: a systematic review. Drugs Aging. 2017;34(12):891-905.

32. Per BL, Taylor AW, Gill TK. Prescription medicines, over-thecounter medicines and complementary and alternative medicines use: a comparison between baby boomers and older South Australians. AIMS Public Health. 2019;6(4):380-95.

33. Brandão GR, Teixeira L, Araújo L, Paúl C, Ribeiro O. Selfmedication in older European adults: prevalence and predictive factors. Arch Gerontol Geriatr. 2020;91:104189.

34. Stone JA, Lester CA, Aboneh EA, Phelan CH, Welch LL, Chui MA. A preliminary examination of over-the-counter medication misuse rates in older adults. Res Soc Adm Pharm. 2017;13(1): 187-92.

35. Agbabiaka TB, Spencer NH, Khanom S, Goodman C. Prevalence of drug-herb and drug-supplement interactions in older adults: a cross-sectional survey. Br J Gen Pract. 2018;68(675):e711-7.

36. Lockett J, Sauma S, Radziszewska B, Bernard MA. Adequacy of inclusion of older adults in NIH-funded phase III clinical trials. J Am Geriatr Soc. 2019;67(2):218-22 Analysed the representation of older adults in phase III clinical trials funded by the National Institutes for Health from 1965 to 2015 that addressed top causes for hospitalisation and/or disabilityadjusted life years in older adults. Results indicated that older adults were excluded from studies through both explicit (e.g. arbitrary upper age limits) and implicit (e.g. based on various comorbid conditions such as polypharmacy/concomitant medication or cardiac issues) factors thus disproportionately underrepresenting older adults.

37. Ruiter R, Burggraaf J, Rissmann R. Under-representation of elderly in clinical trials: an analysis of the initial approval documents in the Food and Drug Administration database. Br J Clin Pharmacol. 2019;85(4):838-44.

38. van Marum RJ. Underrepresentation of the elderly in clinical trials, time for action. Br J Clin Pharmacol. 2020;86(10):2014-6.

39. Florisson S, Aagesen EK, Bertelsen AS, Nielsen LP, Rosholm JU. Are older adults insufficiently included in clinical trials? An umbrella review. Basic Clin Pharmacol Toxicol. 2021;128(2): 213-23.

40. Bourgeois FT, Orenstein L, Ballakur S, Mandl KD, Ioannidis JPA. Exclusion of elderly people from randomised clinical trials of drugs for ischaemic heart disease. J Am Geriatr Soc. 2017;65(11):2354-61.

41. Nguyen QD, Peters E, Wassef A, Desmarais P, RémillardLabrosse D, Tremblay-Gravel M. Evolution of age and female representation in the most-cited randomised controlled trials of cardiology of the last 20 years. Circ Cardiovasc Qual Outcomes. 2018;11(6):e004713.

42. Vitale C, Fini M, Spoletini I, Lainscak M, Seferovic P, Rosano GMC. Under-representation of elderly and women in clinical trials. Int J Cardiol. 2017;232:216-21.

43. Hanlon P, Hannigan L, Rodriguez-Perez J, Fischbacher C, Welton NJ, Dias S, et al. Representation of people with comorbidity and multimorbidity in clinical trials of novel drug therapies: an individual-level participant analysis. BMC Med. 2019;17:201.

44. He J, Morales DR, Guthrie B. Exclusion rates in randomised controlled trials of treatments of physical conditions: a systematic review. Trials. 2020;21:228 Systematic review of 50 studies which reported exclusion rates from 305 randomised controlled trials of treatments in 31 physical conditions. Findings indicated that the most commonly applied exclusion criteria related to age, co-morbidity, and co-prescribing.

45. Kuchel GA. Inclusion of older adults in research: ensuring relevance, feasibility, and rigor. J Am Geriatr Soc. 2019;67(2):203-4.

46. Prendki V, Tau N, Avni T, Falcone M, Huttner A, Kaiser L, et al. ESCMID Study Group for Infections in the Elderly (ESGIE). A systematic review assessing the under-representation of elderly adults in COVID-19 trials. BMC Geriatr. 2020;20:538.

47. Helfand BKI, Webb M, Gartaganis SL, Fuller L, Kwon C-S, Inouye SK. The exclusion of older persons from vaccine and treatment trials for coronavirus disease 2019 - missing the target. JAMA Intern Med. 2020;180(11):1546-9.

48. Jaoude JA, Kouzy R, El Alam MB, Subbiah V, Taniguchi CM, Ludmir EB. Exclusion of older adults in COVID-19 clinical trials. Mayo Clin Proc. 2020;95(10):2293-4.

49. Tisminetzky M, Delude C, Hebert T, Carr C, Goldberg RJ, Gurwitz JH. Age, multiple chronic conditions, and COVID-19: a literature review. J Gerontol A Biol Sci Med Sci. 2020. https:// doi.org/10.1093/gerona/glaa320.

50. Richardson SJ, Carroll CB, Close J, Gordon AL, O’Brien J, Quinn TJ, et al. Research with older people in a world with COVID-19: identification of current and future priorities, challenges and opportunities. Age Ageing. 2020;49(6):901-6.

51. Vaughan CP, Dale W, Allore HG, Binder EF, Boyd CM, Bynum JPW, et al. AGS report on engagement related to the NIH inclusion across the lifespan policy. J Am Geriatr Soc. 2019;67(2):2117.

52. Food and Drug Administration. Inclusion of older adults in cancer clinical trials: guidance for industry. 2020. Available at: https:// www.fda.gov/media/135804/download. Accessed 26 Mar 2021

53. Nanna MG, Chen ST, Nelson AJ, Navar AM, Peterson ED. Representation of older adults in cardiovascular disease trials since the inclusion across the lifespan policy. JAMA Intern Med. 2020;180(11):1531-3.

54. DeJong C, Covinsky K. Inclusion across the lifespan in cardiovascular trials - a long road ahead. JAMA Intern Med. 2020;180(11): 1533-4. 
55. Ludmir EB, Subbiah IM, Mainwaring W, Miller AB, Lin TA, Jethanandani A, et al. Decreasing incidence of upper age restriction enrolment criteria among cancer clinical trials. J Geriatr Oncol. 2020;11(3):451-4.

56. Cadogan CA, Ryan C, Hughes CM. Appropriate polypharmacy and medicine safety: when many is not too many. Drug Saf. 2016;39(2):109-16.

57. Masnoon N, Shakib S, Kalisch-Ellett L, Caughey GE. What is polypharmacy? A systematic review of definitions BMC Geriatr. 2017;17:230.

58. Sirois C, Domingues NS, Laroche M-L, Zongo A, Lunghi C, Guénette L, et al. Polypharmacy definitions for multimorbid older adults need stronger foundations to guide research, clinical practice and public health. Pharmacy. 2019;7(3):126.

59. Midāo L, Giardini A, Menditto E, Kardas P, Costa E. Polypharmacy prevalence among older adults based on the survey of health, ageing and retirement in Europe. Arch Gerontol Geriatr. 2018;78:213-20 Cross-sectional analysis of data from Wave 6 of the Survey of Health, Ageing and Retirement in Europe database, spanning 17 European countries. The findings showed a range in the prevalence of polypharmacy $(\geq 5$ medications) from 26.3 to $39.9 \%$. A number of significant variables (e.g. age, gender, number of chronic diseases, difficulty in taking medications) were found to be associated with polypharmacy and may help to identify those most vulnerable to polypharmacy to whom interventions should be targeted.

60.• Morin L, Johnell K, Laroche M-L, Fastbom J, Wastesson JW. The epidemiology of polypharmacy in older adults: register-based prospective cohort study. Clin Epidemiol. 2018;10:289-98 Large, prospective cohort study of $1,742,336$ older adults in Sweden. Prevalence of polypharmacy ( $\geq 5$ drugs) was $44.0 \%$ and prevalence of excessive polypharmacy ( $\geq 10$ drugs) was $11.7 \%$. Higher age, more chronic disease, and multi-dose dispensing led to a more frequent exposure to polypharmacy. Findings suggest that interventions to reduce polypharmacy should not only focus on patients already exposed to polypharmacy, but also include prevention strategies to reduce the number of incident cases.

61. Page AT, Falster MO, Litchfield M, Pearson S-A, Etherton-Beer C. Polypharmacy among older Australians, 2006-2017: a population-based study. Med J Aust. 2019;211(2):71-5.

62. Ellenbogen MI, Wang P, Overton HN, Fahim C, Park A, Bruhn WE, et al. Frequency and predictors of polypharmacy in US Medicare patients: a cross-sectional analysis at the patient and physician levels. Drugs Aging. 2020;37(1):57-65.

63. Falster MO, Charrier R, Pearson S-A, Buckley NA, Daniels B. Long-term trajectories of medicine use among older adults experiencing polypharmacy in Australia. Br J Clin Pharmacol. 2021;87(3):1264-74.

64. Hughes C. Appropriate and inappropriate polypharmacy - choosing the right strategy. Br J Clin Pharmacol. 2021;81(1):84-6.

65. Brett J, Pearson S-A, Daniels B, Wylie CE, Buckley NA. A crosssectional study of psychotropic medicine use in Australia in 2018: a focus on polypharmacy. Br J Clin Pharmacol. 2021;87(3):136977.

66. Slater N, White S, Frischer M. Central nervous system (CNS) medications and polypharmacy in later life: cross-sectional analysis of the English Longitudinal Study of Ageing (ELSA). BMJ Open. 2020;10:e034346.

67. Zhang X, Zhou S, Li X, Zhou W, Zhou Y, Cui Y, et al. Anticholinergic and sedative medications exposure in older patients: a cross-sectional study. Int J Clin Pharm. 2019;41(5):11528.

68. Mafi JN, May FP, Kahn KL, Chong M, Corona E, Yang L, et al. Low-value proton pump inhibitor prescriptions among older adults at a large academic health system. J Am Geriatr Soc. 2019;67(12):2600-4.

69. Cooper JA, Moriarty F, Ryan C, Smith SM, Bennett K, Fahey T, et al. Potentially inappropriate prescribing in two populations with different socio-demographic profiles: a cross-sectional database study using the PROMPT criteria. Eur J Clin Pharmacol. 2016;72(5):583-91.

70. Jirón M, Pate V, Hanson LC, Lund JL, Funk MJ, Stürmer T. Trends in prevalence and determinants of potentially inappropriate prescribing in the United States: 2007 to 2012. J Am Geriatr Soc. 2016;64(4):788-97.

71. Cho H, Choi J, Kin Y-S, Son SJ, Lee KS, Hwang H-J, et al. Prevalence and predictors of potentially inappropriate prescribing of central nervous system and psychotropic drugs among elderly patients: a national population study in Korea. Arch Gerontol Geriatr. 2018;74:1-8.

72. Hansen CR, Byrne S, Cullinan S, O'Mahony D, Sahm LJ, Kearney PM. Longitudinal patterns of potentially inappropriate prescribing in early old-aged people. Eur J Clin Pharmacol. 2018;74(3):307-13.

73. Lopez-Rodriguez JA, Rogero-Blanco E, Aza-Pascual-Salcedo M, Lopez-Verde F, Pico-Soler V, Leiva-Fernandez F, et al. Potentially inappropriate prescriptions according to explicit and implicit criteria in patients with multimorbidity and polypharmacy. MULTIPAP: a cross-sectional study. PLoS One. 2020;15(8):e0237186

74. Barry HE, Cooper JA, Ryan C, Passmore AP, Robinson AL, Molloy GJ, et al. Potentially inappropriate prescribing among people with dementia in primary care: a retrospective cross-sectional study using the Enhanced Prescribing Database. J Alzheimers Dis. 2016;52(4):1503-13.

75. Herr M, Grondin H, Sanchez S, Armaingaud D, Blochet C, Vial A, et al. Polypharmacy and potentially inappropriate medications: a cross-sectional analysis among 451 nursing homes in France. Eur J Clin Pharmacol. 2017;73(5):601-8.

76. Rochon PA, Gurwitz JH. The prescribing cascade revisited. Lancet. 2017;389(10081):1778-80.

77. McCarthy LM, Visentin JD, Rochon PA. Assessing the scope and appropriateness of prescribing cascades. J Am Geriatr Soc. 2019;67(5):1023-6.

78. Mangin D, Lawson J, Cuppage J, Shaw E, Ivanyi K, Davis A, et al. Legacy drug-prescribing patterns in primary care. Ann Fam Med. 2018;16(6):515-20.

79. Von Buedingen F, Hammer MS, Meid AD, Muller WE, Gerlach FM, Muth C. Changes in prescribed medicines in older patients with multimorbidity and polypharmacy in general practice. BMC Fam Pract. 2018;19:131.

80. Mangin D, Bahat G, Golomb BA, Mallery LH, Moorhouse P, Onder $\mathrm{G}$, et al. International group for reducing inappropriate medication use and polypharmacy (IGRIMUP): position statement and 10 recommendations for action. Drugs Aging. 2018;35(7):575-87.

81. Gast A, Mathes T. Medication adherence influence factors - an (updated) overview of systematic reviews. Syst Rev. 2019;8:112.

82. Kim SJ, Kwon OD, Han EB, Lee CM, Oh S-W, Joh H-K, et al. Impact of number of medications and age on adherence to antihypertensive medications: a nationwide population-based study. Medicine. 2019;98(49):e17825.

83. Easthall C. Medication nonadherence as a complex health behaviour: there is more to it than just missed doses. J Am Geriatr Soc. 2019;67(12):2439-40.

84. Chung GC, Marottoli RA, Cooney LM, Rhee TG. Cost-related medication nonadherence among older adults: findings from a nationally representative sample. J Am Geriatr Soc. 2019;67(12): 2463-73. 
85. McLoughlin A, Bennett K, Cahir C. Developing a model of the determinants of medication nonadherence in older communitydwelling patients. Ann Behav Med. 2019;53(11):942-54.

86. Alldred DP, Kennedy MC, Hughes C, Chen TF, Miller O. Interventions to optimising prescribing for older people in care homes. Cochrane Database Syst Rev. 2016;2(2):CD009095.

87. Rankin A, Cadogan CA, Patterson SM, Kerse N, Cardwell CR, Bradley MC, et al. Interventions to improve the appropriate use of polypharmacy for older people. Cochrane Database Syst Rev. 2018;9(9):CD008165.

88. Cross AJ, Elliott RA, Petrie K, Kuruvilla L, George J. Interventions for improving medication-taking ability and adherence in older adults prescribed multiple medications. Cochrane Database Syst Rev. 2020;5(5):CD012419.

89. Craig P, Dieppe P, Macintyre S, Michie S, Nazareth I, Petticrew M. Developing and evaluating complex interventions: the new Medical Research Council guidance. BMJ. 2008;337:a1655.

90. Patton DE, Hughes CM, Cadogan CA, Ryan CA. Theory-based interventions to improve medication adherence in older adults prescribed polypharmacy: a systematic review. Drugs Aging. 2017;34(2):97-113.

91. McCarthy C, Clyne B, Corrigan D, Boland F, Wallace E, Moriarty $F$, et al. Supporting prescribing in older people with multimorbidity and significant polypharmacy in primary care (SPPiRE): a cluster randomised controlled trial protocol and pilot. Implement Sci. 2017;12:99.

92. Patton DE, Pearce CJ, Cartwright M, Smith F, Cadogan CA, Ryan $\mathrm{C}$, et al. A non-randomised pilot study of the Solutions for Medication Adherence Problems (S-MAP) intervention in community pharmacies to support older adults adhere to multiple medications. Pilot Feasibility Stud. 2021;7:18.

93. Rankin A, Cadogan CA, Barry HE, Gardner E, Agus A, Molloy GJ, et al. PolyPrime team. An external pilot cluster randomised controlled trial of a theory-based intervention to improve appropriate polypharmacy in older people in primary care (PolyPrime): study protocol. Pilot Feasibility Stud. 2021;7:77.

94. O'Donnell LK, Gnjidic D, Sawan M, Reeve E, Kelly PJ, Chen TF, et al. Impact of the goal-directed medication review electronic decision support system on drug burden index: a clusterrandomised clinical trial in primary care. Br J Clin Pharmacol. 2021;87(3):1499-511.

95. Rieckert A, Reeves D, Altiner A, Drewelow E, Esmail A, Flamm $\mathrm{M}$, et al. Use of an electronic decision support tool to reduce polypharmacy in elderly people with chronic diseases: cluster randomised controlled trial. BMJ. 2020;369:m1822.

96. Ulley J, Harrop D, Ali A, Alton S, Fowler DS. Deprescribing interventions and their impact on medication adherence in community-dwelling older adults with polypharmacy: a systematic review. BMC Geriatr. 2019;19:15.

97. Zechman S, Senn O, Valeri F, Essig S, Merlo C, Rosemann T, et al. Effect of a patient-centred prescribing procedure in older multimorbid patients in Swiss primary care - a cluster randomised clinical trial. BMC Geriatr. 2020;20:471.

98. Kua C-H, Mak VSL, Lee SWH. Health outcomes of deprescribing interventions among older residents in nursing homes: a systematic review and meta-analysis. J Am Med Dir Assoc. 2019;20(3): $362-72$.
99. Bloomfield HE, Greer N, Linskey AM, Bolduc J, Naidl T, Vardeny O, et al. Deprescribing for community-dwelling older adults: a systematic review and meta-analysis. J Gen Intern Med. 2020;35(11):3323-32.

100. Anderson K, Foster MM, Freeman CR, Scott IA. A multifaceted intervention to reduce inappropriate polypharmacy in primary care: research co-creation opportunities in a pilot study. Med J Aust. 2016;204(7):41-4.

101. Burt J, Elmore N, Campbell SM, Rodgers S, Avery AJ, Payne RA. Developing a measure of polypharmacy appropriateness in primary care: systematic review and expert consensus study. BMC Med. 2018;16:91.

102. Brockmöller J, Stingl JC. Multimorbidity, polypharmacy and pharmacogenomics in old age. Pharmacogenomics. 2017;18(6): 515-7.

103. Kocbec S, Kocbek P, Stozer A, Zupanic T, Groza T, Stiglic G. Building interpretable models for polypharmacy prediction in older chronic patients based on drug prescription records. Peer J. 2018;6:e5765.

104. Wilfing D, Hinz A, Steinhäuser J. Big data analysis techniques to address polypharmacy in patients - a scoping review. BMC Fam Pract. 2020;21:180.

105. Beuscart J-B, Pont LG, Thevelin S, Boland B, Dalleur O, Rutjes AWS, et al. A systematic review of the outcomes reported in trials of medication review in older patients: the need for a core outcome set. Br J Clin Pharmacol. 2017;83(5):942-52.

106. Millar A, Rankin A, McGrattan M, Spargo M, Hughes CM. The role of Core Outcome Sets for pharmaceutical care research. In: Alves da Costa F, Van Mil JWF, Alvarez-Risco A, editors. The pharmacist guide to implementing pharmaceutical care. Springer; 2019. pp. $129-140$

107. Millar AN, Daffu-O'Reilly A, Hughes CM, Alldred DP, Barton G, Bond CM, et al. Development of a core outcome set for effectiveness trials aimed at optimising prescribing in older adults in care homes. Trials. 2017;18(1):175.

108. Beuscart J-B, Knol W, Cullinan S, Schneider C, Dalleur O, Boland $\mathrm{B}$, et al. International core outcome set for clinical trials of medication review in multi-morbid older adults with polypharmacy. BMC Med. 2018;16:21.

109. Smith SM, Wallace E, Salisbury C, Sasseville M, Bayliss E, Fortin M. A core outcome set for multimorbidity research (COSmm). Ann Fam Med. 2018;16(2):132-8.

110. Rankin A, Cadogan CA, Ryan C, Clyne B, Smith SM, Hughes $\mathrm{CM}$. Core Outcome Set for trials aimed at improving the appropriateness of polypharmacy in older people in primary care. J Am Geriatr Soc. 2018;66(6):1206-12.

111. McGrattan M, Barry HE, Ryan C, Cooper JA, Passmore AP, Robinson AL, et al. The development of a core outcome set for medicines management interventions for people with dementia in primary care. Age Ageing. 2019;48(2):260-6.

112. Aubert CE, Kerr EA, Maratt JK, Klamerus ML, Hofer TP. Outcome measures for interventions to reduce inappropriate chronic drugs: a narrative review. J Am Geriatr Soc. 2020;68(10):2390-8.

Publisher's Note Springer Nature remains neutral with regard to jurisdictional claims in published maps and institutional affiliations. 